\title{
LAS INDIAS EN LA VIDA Y NEGOCIOS DE MURILLO
}

\section{THE INDIES IN MURILLO’S LIFE AND BUSINESSES}

\author{
José Manuel Cruz Valdovinos \\ Universidad Complutense Madrid. España \\ josemanuelcruzvaldovinos@ghis.ucm.es
}

\begin{abstract}
Parece que están claras las razones de la temprana decisión de Murillo de embarcarse hacia Tierra Firme, aunque no las que le hicieron desistir. Hemos construido una hipótesis novedosa sobre el asunto. Estudiamos los negocios de préstamo del pintor a diversos tipos de personas relacionadas con el tráfico americano, con peculiaridades interesantes como la ocultación bajo su nombre de la identidad de algunos prestamistas nobles o vinculados a puestos oficiales en la Casa de Contratación. Nos ocupamos de su biografía, las vicisitudes que experimentaron dichos préstamos y también algunos contratos de provisión de bastimentos para buques que llevó a cabo Murillo.

Palabras clave: Murillo; Veitia; préstamos; testaferro; flota.
\end{abstract}

The reasons for Murillo's early decision to embark towards Dry Land seem to be clear. Those which made him desist, not so much. We are proposing a novel theory on this issue. We have studied the painter's businesses lending money to various types of people related to trade with America. Some interesting curiosities have come up, such as the fact that several noblemen or officials related to the House of Trade of the Indies borrowed money from him concealing their identity. We deal with the painter's biography, the vicissitudes of those loans and some supply contracts for boats concluded by Murillo.

Keywords: Murillo; Veitia; loans; front man; fleet.

\section{LAS INDIAS, UN DESTINO TENTADOR PARA EL JOVEN MURILLO}

Bartolomé Esteban Murillo tuvo como primer proyecto vital la carrera de Indias, como tantos muchachos sevillanos que marchaban con la idea de prosperar en ese mundo de aventuras y negocios. En la carta de cesión de mejoras -como la denomina el escribano- de 18 de abril de 1633 a favor de su prima Tomasa Murillo, se declaraba "de partida para la provincia de Tierra Firme de las Indias en los galeones que de próximo se aprestan para ella del cargo del general 
el marqués de Cadereyta". El padre del pintor había arrendado en 1613 por dos vidas al convento de Santo Domingo las casas donde nacería Murillo, inmediatas al convento, y le había señalado en su testamento como segundo arrendatario. El derecho a cobrar las mejoras hechas en esas casas, que debían de ser satisfechas por el convento cuando se extinguiera la segunda vida, eran los únicos bienes que tenía entonces y disponía de ellos a favor de su prima para caso de muerte ${ }^{2}$. A pesar de su juventud, era consciente de los peligros que rodeaban al viaje.

La decisión de marchar a América puede explicarse, como ya lo apuntó Angulo $^{3}$, por la relación que tenía con el Nuevo Mundo su tutor y cuñado, el cirujano Juan Agustín Lagares, casado con Ana Murillo, con los que convivió el pintor tras la muerte de sus padres cuando tenía nueve años. Documentos conocidos después de que escribiera Angulo confirman que Lagares ejercía como prestamista y fiador de cargadores a Indias ${ }^{4}$. La suposición de Angulo se fundamentaba, entre otras circunstancias, en un poder que había otorgado Lagares el 14 de abril de 1633 - cuatro días antes que el pintor otorgara su cesión- a favor de Bartolomé Ortiz, residente en Sevilla, que marchaba a Nueva España en la armada de don Lope de Hoces. Le encargaba que gestionara el cobro de la herencia de su hermano Sebastián, que había muerto en Nueva Veracruz, así como el recobro de ciertos bienes que le había enviado para vender ${ }^{5}$. A este dato objetivo del hermano emigrante, Angulo añadía la suposición de que el apoderado era Bartolomé Pérez Ortiz, hijo del hermano de la madre de Murillo y también pintor, Antonio Pérez. Pero, como el mismo estudioso señalaba, su tumba, conservada en la catedral de Sevilla de la que era racionero, indica que falleció en 1678 a los 64 años, lo que implica que en 1633 tenía 19. Conviene recordar que la mayoría de edad se alcanzaba entonces a los 25 años, por lo que difícilmente hubiera podido atender a una gestión de ese tipo.

Otros datos manejados por Angulo apuntan en el sentido de que la familia de Murillo contaba con otras experiencias en el viaje americano. El albacea del difunto Sebastián Lagares se llamaba Juan Esteban, residente en la citada ciudad novohispana, quizá uno de los hermanos mayores del pintor, y otra de sus hermanas, María, estaba tramitando en 1633 la información de limpieza de sangre junto

${ }^{1}$ ANGUlo ÍÑIGUEZ, Diego: "El viaje de Murillo a Tierra Firme en 1633", $A r$ chivo Español de Arte, 183, 1973, pp. 354-357.

${ }^{2}$ HEREZA, Pablo: Corpus Murillo. Biografía y documentos. Sevilla, 2017, p. 161, doc. 6. Las fuentes documentales serán citadas por esta obra, que incluye, además de las transcripciones revisadas, la referencia de citas en publicaciones.

3 ANGULO ÍÑIGUEZ, Diego: "El viaje...”, op. cit., pp. 356-357.

${ }^{4}$ HEREZA, Pablo: Corpus..., op. cit., p. 28, nota 20, reseña algunos contratos de Lagares relacionados con negocios en América y Filipinas.

5 ANGULO ÍÑIGUEZ, Diego: Murillo. Su vida, su arte, su obra. T. I. Madrid, 1981, pp. 23 y 147. 
a su marido, el cirujano Gerónimo Díaz de Pavía, para pasar a Santo Domingo en La Española. En el testamento que Juan Agustín Lagares otorga el 17 de octubre de 1656 manifiesta que había criado y alimentado a los dos hijos del anterior matrimonio de Ana Murillo, llamados Luis Sánchez Carrascosa y Tomasa Murillo, y que a Luis le había enviado a la escuela y dado estudios "hasta que pasó a las Indias, que sería de edad de doce años". Su padrastro afirmaba que, en aquel momento, Luis era racionero de la catedral de Quito ${ }^{6}$. El destino de su viaje había sido, por tanto, la llamada Tierra Firme, desembarcando en Cartagena de Indias o Portobelo, donde solían recalar las flotas, para marchar luego hacia el Perú. Angulo calculó que estaba en América antes de 1633 y que pudo ser otro de los motivos de la decisión del futuro pintor. Hereza calcula que el primer matrimonio de Ana Murillo se celebró en 1617 y que Luis nació hacia $1620^{7}$.

En nuestra opinión, además de que Bartolomé Ortiz, el apoderado de Lagares, no debía de ser el primo del pintor por su minoría de edad, tal como hemos apuntado, el texto del poder dice que se dirigía a Nueva España en la armada de Lope de Hoces ${ }^{8}$, lo que es lógico, pues la herencia de Sebastián Lagares se liquidaría en Nueva Veracruz. Por el contrario, Murillo se dirigía a Tierra Firme en la armada del marqués de Cadreita. Por ser este su destino, pensamos que su idea era reunirse con su primo Luis Sánchez Carrascosa, que podía estar ya en Quito o le esperaba para marchar. Si había nacido en fechas cercanas a las de Murillo y había marchado a América con 12 años, tuvo que hacerlo en 1631, porque en 1632 no salió la flota9.

Hereza apunta como posibles razones para el viaje de Murillo una decisión de Juan Agustín Lagares, que enviaba al Nuevo Mundo a sus dos parientes para recobrar la herencia de Sebastián Lagares, y, por ello, supone que, si se frustró, fue porque se había solucionado de otro modo el asunto que les llevaba alli ${ }^{10}$.

Sobre el desistimiento, tenemos una hipótesis diferente. José de Veitia Linaje, el que sería marido de la citada Tomasa Murillo, escribía en su obra Norte de la Contratación - pasados más de cuarenta años de estos hechos- sobre la inseguridad del puerto de Cádiz, y, entre otros ejemplos, citaba que "en el de 1633, a 6 de mayo, la mayor parte de las Naos de la flota que estaba para salir aquel año

${ }^{6}$ HEREZA, Pablo: Corpus..., op. cit., pp. 314-320, doc. 86.

7 Ibidem, p. 26. Las fechas son aproximadas.

8 ANGULO ÍNIIGUEZ, Diego: Murillo..., op. cit., t. I, p. 147; y HEREZA, Pablo: Corpus..., op. cit., p. 30, nota 25. Refiriéndose a los poderes de Lagares, señala que "por los documentos anteriores no podemos confirmar esta hipótesis".

${ }^{9}$ LANG, Mervin Francis: Las flotas de la Nueva España (1630-1710). Despacho, azogue, comercio. Sevilla-Bogotá, 1998, pp. 121-122.

${ }^{10}$ HEREZA, Pablo: Corpus..., op. cit., pp. 30-31. 
desde la Baia de Cádiz [se hundieron]"11. Fernández Duro habla de once naos perdidas antes de salir de Cádiz ${ }^{12}$. El Consejo de Indias, además, decidió ese año que la Armada de los galeones que acompañaba a las flotas para defenderlas "no se limitara a escoltarlas, sino que aprovechara el viaje y deshiciera alguna de las guaridas de corsarios..." ${ }^{13}$. Con tal fin, se unieron los galeones de Cadreita -que, inicialmente, iban a acompañar la flota a Tierra Firme- y los de Lope de Hoces -que iban a hacerlo con la de Nueva España-y, con algunos generales y militares más, salieron el 12 de mayo de Cádiz con 24 galeones. La flota que protegían estaba compuesta de 31 naos. Llevaban orden de marchar primero contra la isla de San Martín, ocupada por los holandeses. Al llegar a las inmediaciones, se ordenó que las naos anclaran fuera del lugar donde podía alcanzarles el fuego y los galeones trabaron batalla contra los que defendían la isla, luchando desde el 24 de junio hasta el 1 de julio en que se rindió la guarnición. Se organizó la ocupación española de San Martín y, después, la flota siguió su viaje a Nueva España. Hay, por tanto, dos razones al menos para que Murillo se quedara en tierra. La nao en la que tenía previsto viajar pudo ser una de las que se hundieron ${ }^{14} \mathrm{y}$, más seguro y determinante, es que la flota de ese año no iba a hacer puerto en Tierra Firme, sino solo en Nueva España. Hasta que surgió una nueva oportunidad de marchar a su destino pasaron más de dos años ${ }^{15} \mathrm{y}$, mientras tanto, Murillo debió de cambiar sus proyectos.

Empieza en 1633 un largo periodo en que carecemos de datos sobre el pintor. Rompe el silencio la noticia de 7 de febrero de 1644, en que se recibe como hermano de la Cofradía del Rosario, sita en el convento dominico de San Pablo el Real, propietario de su casa natal. Sabemos por las declaraciones de testigos en su expediente matrimonial de 1645 que, hasta entonces, no había hecho ausencias

${ }^{11}$ DE VEITIA LINAJE, José: Norte de la Contratación de las Indias Occidentales. Sevilla, 1671, p. 62.

12 FERNÁNDEZ DURO, Cesáreo: Historia de la Armada española desde la unión de los Reinos de Castilla y León. T. IV. Madrid, 1898, pp. 112-117, en especial p. 112. http:// www.armada.mde.es/html/historiaarmada/tomo4/tomo_04_08.pdf (Consultado el 19-62018).

13 Ibidem, pp. 112-113.

${ }^{14}$ Aunque Murillo afirma que va a embarcarse en los galeones, que eran naves militares, es claro que no iba alistado como marinero, pues no hubiera dicho que viajaba a Tierra Firme.

${ }^{15}$ La flota de Tierra Firme de 1644 no salió -solo había una al año con ese destino-, sino solo la Armada, al mando del general Jerónimo Gómez de Sandoval. La flota de 1645 salió de Cádiz el 3 de julio llevando, además de las naves capitana y almiranta, la protección de la Armada al mando del general don Pedro de Ursúa. LANG, Mervin Francis: Las flotas..., op. cit., p. 142. 
notables de Sevilla ${ }^{16}$. En febrero de este año se declara por primera vez pintor ${ }^{17}$. No cabe duda que, después de 1633, se dedicó a la práctica de la pintura, en la que posiblemente tenía ya algunos conocimientos ${ }^{18}$. Sus primeras obras -para los dominicos- se suelen datar entre 1638 y 1640 y muestran ya un gran dominio técnico.

Pero el ejercicio de su profesión de pintor no le impediría seguir siendo partícipe en la carrera de Indias, si bien sin salir de Sevilla. Profundizaría su relación con el comercio americano tras emparentar en 1644 con el citado burgalés José de Veitia Linaje ${ }^{19}$, que entonces era solo un oficial de Andrés Munibe, el tesorero de la Casa de Contratación, pero muy hábil y con gran futuro; en 1649, el tesorero le haría su oficial mayor y en 1653 Veitia pagaba 60.000 reales de plata para comprar el oficio de contador de averías de la Casa, que gozaba de un importante sueldo anual ${ }^{20}$. Al desposorio de Tomasa y José de Veitia asistió como testigo el platero Tomás de Villalobos, tío y protector de Beatriz de Cabrera, que al año siguiente casaría con Murillo, y fue padrino de las velaciones don Jerónimo de San Víctores ${ }^{21}$, ilustre burgalés que había sido poco antes designado

${ }^{16}$ HEREZA, Pablo: Corpus..., op. cit., pp. 171-176, doc. 11.

${ }^{17}$ La declaración del propio Murillo de que es "pintor de imaginería" se incluye en la carta de dote a favor de Beatriz de Cabrera de 24 de febrero de 1645. HEREZA, Pablo: Corpus..., op. cit., pp. 176-180, doc. 12.

${ }^{18}$ El ya citado Antonio Pérez, hermano de su madre, era pintor. Murió en 1631, cuando Murillo tenía 13 años, y pudo aprender con él las primeras nociones de pintura. Sus dos hijas estaban casadas con los pintores Francisco Terrón y Juan del Castillo, con los que proseguiría el aprendizaje, más probable con Castillo, y después pudo pasar por el obrador de Francisco de Zurbarán. ANGULO ÍÑIGUEZ, Diego: Murillo..., op. cit., pp. 25-27; y HEREZA, Pablo: Corpus..., op. cit., pp. 23-24.

19 José de Veitia y Tomasa Murillo fueron los padrinos de velaciones de Murillo con Beatriz de Cabrera el 6 de septiembre de 1645. HEREZA, Pablo: Corpus..., op. cit., p. 188, doc. 16. Entre 1648 y 1650, Murillo y Veitia vivieron en casas cercanas, en la calle Corral del Rey, collación de San Isidoro. HEREZA, Pablo: Corpus..., op. cit., pp. 64-65.

${ }^{20}$ VILA VILAR, Enriqueta: El tesorero Andrés Munibe. Entre la Casa y el Consulado, en VILA VILAR, Enriqueta; ACOSTA RODRÍGUEZ, Antonio y GONZÁLEZ RODRÍGUEZ, Adolfo Luis (coords.): La Casa de la Contratación y la navegación entre España y las Indias. Sevilla, 2004, pp. 433-447, en especial la p. 437, nota 14. En 1649, para entrar a ejercer la oficialía, fue obligado a prestar una fianza de 10.000 ducados, a la que contribuyeron su esposa y el tío de esta, el platero Tomás de Villalobos, además de una amplia serie de comerciantes con apellidos vizcaínos, entre ellos el banquero Domingo de Estensoro Cortázar, que, al igual que Villalobos, afianzó por valor de 500 ducados. Este banquero aparece citado en la carta que dirige Francisco de Zurbarán a Murillo el 27 de septiembre de 1659. CRUZ VALDOVINOS, José Manuel: "Murillo en Madrid", Anales del Instituto de Estudios Madrileños, LVII, 2017, p. 289.

${ }^{21}$ Partida de desposorio y velaciones publicada en MONTOTO, Santiago: D. José de Veitia Linaje y su libro Norte de Contratación de las Indias. Sevilla, 1921, p. 12, nota 1. 
administrador de la Aduana de Sevilla y cuyo hijo José tuvo una importante relación con el pintor ${ }^{22}$.

La hija de Ana Murillo y Juan Agustín Lagares, llamada Juana, casó hacia 1646 con José Aturiac, de origen francés, un agente de negocios indiano que había viajado a Portobelo varias veces antes de 1650, en que murió. Precisamente, en este viaje llevaba poderes de Murillo y Veitia relacionados con préstamos marítimos de los que tratamos después ${ }^{23}$.

Pronto llegó la ocasión de que se pusieran en contacto los entornos artísticos y comerciales del pintor. El suceso se produjo el 24 de marzo de 1646, en que $\mathrm{Mu}-$ rillo bautizó a su primer vástago, una niña llamada María. El padrino fue Jorge de Cuadros, el acaudalado suegro de Juan de Zurbarán, una noticia que puede tener algún recorrido en el análisis del estilo temprano de Murillo ${ }^{24}$. Pero, a la vez, Cuadros formaba parte de los numerosos mercaderes o hijos de mercaderes enriquecidos $^{25}$ que se dedicaban al préstamo, como bien supuso Caturla ${ }^{26}$. El afecto de Murillo por el financiero provendría de alguna relación económica que habría existido entre ambos. A la vista de la actividad del pintor en el decenio 1650-1660, en que se tiene noticia de numerosas operaciones "indianas", parece probable que se desarrollara en el mismo contexto.

\section{OPERACIONES MERCANTILES DE MURILLO RELACIONADAS CON INDIAS}

El tipo de negocios americanos al que el pintor se dedicó durante algunos años no tuvo nada que ver con la fórmula usual entre sus colegas sevillanos, que era la de enviar partidas de pinturas a los puertos americanos a cargo de intermediarios

${ }^{22}$ CRUZ VALDOVINOS, José Manuel: "Notas sobre la clientela de Murillo", en Murillo 400 años. Congreso internacional. Sevilla, 2019, pp. 191-198. Establecemos la identificación del retrato de un caballero de Alcántara conservado en el Metropolitan Museum de Nueva York con José de San Víctores y de la Portilla.

${ }^{23}$ HEREZA, Pablo: Corpus..., op. cit., pp. 26-28.

${ }^{24}$ Ibidem, p. 40.

${ }^{25}$ Posiblemente, Jorge de Cuadros era hijo de Leonís de Cuadros, importante comerciante, dueño de buques y registrado en la matrícula de comerciantes de los años finales del siglo XVI y primeros del XVII. En 1645 aparece afianzando a un comerciante flamenco y declara que tiene 55 años y que es parroquiano de la Iglesia mayor. CRAILSHEIM, Eberhard: The Spanish Connection French and Flemish Merchant Networks in Seville (1570 1650). Colonia-Weimar-Viena, 2016, p. 173. Sobre su riqueza, basta observar que la dote de su hija Mariana al contraer matrimonio con Juan de Zurbarán ascendía a 50.000 reales, más del doble de la dote de Beatriz de Cabrera, la esposa de Murillo, valorada en 22.000 reales. HEREZA, Pablo: Corpus..., op. cit., p. 40.

${ }^{26}$ CATURLA, María Luisa: "Don Juan de Zurbarán”, Boletín de la Real Academia de la Historia, 141, 1957, pp. 269-278, en especial las pp. 171-172. 
que debían de procurar su venta. Palomino refería que "después de haber aprendido, lo que bastaba, para mantenerse pintando de feria (lo cual entonces prevalecía mucho) hizo una partida de pinturas, para cargazón de Indias; y habiendo por este medio adquirido un pedazo de caudal, pasó a Madrid" 27 , y sus afirmaciones han sido tomadas en cuenta por los investigadores. No ha quedado rastro del supuesto envío a Indias, a pesar de que estas remesas solían documentarse ${ }^{28}$, $\mathrm{y}$, en cambio, hay documentación abundante respecto a las diversas operaciones de otro tipo que realizó el pintor. Aunque en el poder que otorga en Madrid el 30 de abril de 1658 para Veitia y Bartolomé Pérez Ortiz $^{29}$ se refiere al cobro de partidas de maravedís y "otras mercaderías" que le debieran en Indias, se refería sin duda al préstamo que había hecho el año anterior al capitán Jerónimo de Cortabarría, una operación que examinamos después con detalle.

Pero también es cierto que el tráfico de pinturas con Indias daba lugar a relaciones muy complejas entre los artífices, con compras y encargos entre ellos ${ }^{30}$, de modo que no puede descartarse totalmente que, en alguna ocasión, vendiera pinturas o trabajara para alguno de los pintores exportadores. En especial, merece la pena considerar la evidente cercanía de Murillo a Juan de Zurbarán, confirmada por la amistad con su suegro, el citado Jorge de Cuadros. La especialización del malogrado pintor en las pequeñas naturalezas muertas, un género muy apreciado entre los clientes americanos ${ }^{31}$, le hace especialmente idóneo para haber

27 PAlOMino DE CASTRO Y VELASCO, Antonio: El Parnaso español. Madrid, 1947, p. 1031.

${ }^{28}$ CRUZ VALDOVINOS, José Manuel: Notas..., op. cit. Es improbable que Murillo tuviera que recurrir a exportar pinturas a Indias para mantenerse, pues la afluencia de clientes sevillanos fue continua.

${ }^{29}$ CRUZ VALDOVINOS, José Manuel: Notas..., op. cit.; y HEREZA, Pablo: Corpus..., op. cit., pp. 341-343, doc. 99.

${ }^{30}$ SÁNCHEZ, José María: "Los obradores artísticos sevillanos del siglo XVI: adaptaciones y cambios para satisfacer los encargos del mercado americano", Anales del Instituto de Investigaciones Estéticas, 103, 2013, pp. 177-196, en especial las pp. 181-182. Proporciona ejemplos de financiación por parte de comerciantes a los artífices, con división de las ganancias.

${ }^{31}$ MALO LARA, Lina: "Aportación documental al catalogo del pintor Francisco López Caro: cuarenta bodegones para Juan Martínez Montañés”, Laboratorio de Arte, 18, 2005, pp. 311-318. Da noticia del contrato de septiembre de 1633 entre Juan Martínez Montañés y Francisco López Caro para que este le hiciera cuarenta lienzos de frutas y alimentos diversos que se relacionan con detalle en el documento, por un total de 1.000 reales, que debía entregar para fin de enero de 1634. Probablemente formarían parte de un envío a Indias más amplio, que incluiría esculturas del obrador de Montañés. Francisco López Caro hizo también otros envíos de pinturas religiosas. En 23 de septiembre de 1647 daba poder a dos peruleros para que cobraran en Perú numerosas pinturas religiosas y un juego de los cinco sentidos que había dado para vender a un agente de negocios. KINKEAD, Duncan T.: Pintores y doradores en Sevilla: 1650-1699 Documentos. 
sido partícipe del tráfico indiano de pinturas, y, sin embargo, como ocurre con Murillo, no se han descubierto de momento documentos que lo confirmen. Podemos ver como probable, sin embargo, que tanto uno como otro exportaran algunas de sus obras a través de Francisco de Zurbarán, del que se sabe que había confiado en 1636 al capitán don Diego de Mirafuentes una larga lista de pinturas para que las vendiera en Portobelo al precio más alto posible. Por el pleito que se desarrolló ante la Casa de la Contratación en 1640, se sabe que debía de venderlas al menos en 2.000 pesos de 8 reales en que estaba fijado su valor en España. En el caso de no conseguirlo, las tenía que entregar a un agente llamado Antonio de Velasco para que las condujera a Lima para venderlas alli ${ }^{32}$. Se conocen los nombres de diversos pintores de segunda fila que fueron llamados como testigos de la entrega al capitán ${ }^{33}$, entre los que debemos ver seguramente a los colaboradores de Zurbarán autores de los cuadros. Pero el precio de 16.000 reales de plata esperado para la partida era muy alto para lo que se acostumbraba en estos envíos ${ }^{34}$,

Bloomington, 2009, p. 281. En su inventario post mortem a 6 de mayo de 1661 aparecen doce Vírgenes de vara de largo que sirven para originales, y otros tantos ángeles de la misma medida que servían para lo mismo. KINKEAD, Duncan T.: Pintores..., ob. cit., pp. 284-285. Los oficiales copiarían de estos modelos, y esa producción de mediano mérito sería la que se enviaba a América.

32 PALOMERO PÁRAMO, Jesús: "Notas sobre el taller de Zurbarán: un envío de lienzos a Portobelo y Lima en 1636", en Extremadura en la evangelización del Nuevo Mundo. Madrid, 1990, pp. 313-330; CATURLA, María Luisa: Francisco de Zurbarán. París, 1994, p. 299, cat. n 71; y NAVARRETE PRIETO, Benito: "La mecánica de trabajo en el obrador de Zurbarán”, en Zurbarán ante su centenario (1598-1998). Valladolid, 1999, pp. 115-145.

${ }^{33}$ Los testigos fueron los pintores José Durán -que declaró que la mayor parte de las obras estaban hechas en casa de Francisco de Zurbarán por su mano y por otros oficiales de lo mejor que había en Sevilla-, el aprendiz de pintor Diego Muñoz Naranjo -que dijo que el capitán había expuesto las pinturas en una fiesta que hubo en el barco, por lo que se dañaron-, Ignacio de Ries -que manifestó que Antonio de Velasco no llegó a recibir las pinturas, porque Mirafuentes las entregó a su propio corresponsal en Lima-, Alonso de Flores y Francisco López, que había embarcado en el galeón de Mirafuentes. PALOMERO PÁRAMO, Jesús: Notas..., op. cit., pp. 320-330.

${ }^{34}$ Aunque posteriores en casi medio siglo, hay algunos ejemplos. Simón Gutiérrez daba recibo en 1690 de 277 escudos de a 10 reales de plata por dos rollos de pinturas que había vendido un agente suyo en Caracas. KINKEAD, Duncan T.: Pintores..., op. cit., p. 235. Esteban Márquez contrató en 13 de febrero de 1694 con un presbítero la hechura de 12 cuadros de gran tamaño ( 5 x 4 varas) de la vida de San Francisco, por 1.335 pesos (entonces equivalentes a 20.000 reales de vellón), a entregar los primeros seis antes de junio para que pudieran salir con la primera flota de Nueva España y el resto en un año. KINKEAD, Duncan T.: Pintores..., op. cit., pp. 309-310. 
por lo que el número de pinturas también debía de serlo ${ }^{35}$, y es posible que incluyera algunas de su hijo Juan y de su amigo Murillo.

\section{Los préstamos marítimos}

En 1650 se produce la primera operación conocida de préstamo naviero de Murillo y su círculo. No eran préstamos a la gruesa, pues no se contemplaba exención alguna del deudor por causa de naufragio, sino préstamos ordinarios. Aunque aparecen como operaciones gratuitas, eran siempre préstamos "a daño", esto es, con interés implícito: el capital a recuperar encubría los intereses pactados y, así, lo entregado al prestatario debió de ser siempre una cifra bastante menor que la deuda adquirida. La ocultación de los intereses era común en la época, por el juicio peyorativo que merecía el préstamo por precio entre particulares, aunque se admitía para los banqueros.

El 6 de abril de 1650, Domingo de Ipeñarrieta, maestre de plata de la nao almiranta, que iba a partir a Tierra Firme en la flota que mandaba Juan de Echeverri, escrituraba un préstamo de 5.520 pesos de 8 reales de plata doble que "por nos acomodar y hacer placer y buena obra" le había hecho Bartolomé Murillo. La devolución se haría en Portobelo antes de fin de julio a quien tuviera poder del prestamista, y si nadie le reclamase allí la cantidad, la devolvería en Sevilla antes de fin de diciembre ${ }^{36}$. La primera posibilidad implicaba una mayor oportunidad de negocio: si se presentaba un apoderado del acreedor en el puerto americano de arribada y cobraba la cantidad estipulada, ello significaba que el tipo real de interés era mayor, pues el préstamo había durado seis meses menos, y, además, el dinero se solía utilizar en la compra de mercancías americanas apreciadas en Castilla, con lo que la ganancia aumentaba con su reventa tras la vuelta de la flota. Al menos una vez, Murillo intentó esta vía de negocio, aunque parece que no llegó a buen término, como luego indicaremos.

El 4 de mayo de 1650, a menos de un mes de la operación anterior, José de Gurmendi, que era maestre de plata de la capitana de los galeones, de camino para Tierra Firme en la misma flota que el anterior, otorgaba un documento semejante al de Ipeñarrieta para reconocer que Murillo le había prestado 4.140 pesos de plata doble y que lo devolvería del mismo modo ${ }^{37}$. La cifra total de los préstamos a ambos capitanes, 9.660 pesos de plata doble, con su equivalencia en

${ }^{35}$ SERRERA, Juan Miguel: “Zurbarán y América”, en Zurbarán. Madrid, 1988, pp. 63-83. Se refiere, por ejemplo, a los 378 lienzos que componían el envío de la viuda de Juan de Luzón en 1660, así como a las características seriadas y de rápida ejecución de las producciones enviadas a América por diversos pintores, entre ellos Zurbarán.

${ }^{36}$ HEREZA, Pablo: Corpus..., op. cit., pp. 231-233, doc. 35.

37 Ibidem, pp. 234-235, doc. 36. 
reales de vellón, 183.540 reales $^{38}$, era una cifra muy alta de dinero que, sin duda, excedía las posibilidades de Murillo.

El día 6 de mayo siguiente, el pintor otorgó poderes a Ipeñarrieta y al maestre de la plata que iba en el galeón de gobierno de la flota, llamado José de Barrutia, para que pudieran cobrar de José de Gurmendi los 4.140 pesos que debía. Acto seguido daba poder a Gurmendi y, por su falta, al capitán Domingo Miguel del Valle, para cobrar los 5.520 pesos que debía Ipeñarrieta ${ }^{39}$.

En el mismo día, pero ante otro escribano, Murillo, ahora juntamente con José de Veitia, dio poder a su respectivo sobrino político y cuñado, José de Aturiac o Aturiaque, para cobrar todo lo que se les debiera a ambos en cualquier punto de Indias $^{40}$. Podemos suponer que Aturiaque tenía, además, encargo de adquirir en Portobelo algunas mercancías con el dinero de los préstamos que restituyeran los maestres y volver con ellas a la Península, lo que completaría el lucro de la operación. Pero la muerte del joven en ese viaje debió de frustrar este proyecto ${ }^{41}$.

Finalmente -lo que constituye la parte más peculiar e interesante de estas dos operaciones de Murillo-, el 27 de mayo, el pintor reconocía en dos escrituras consecutivas que, en la deuda de Ipeñarrieta, de los 5.520 pesos de capital (equivalentes a 44.160 reales de plata doble), correspondían al veedor Juan Martínez de Soto, residente en Cádiz, 22.080 de esos reales, y a Miguel Mejía, vecino de Cádiz, otros 5.520. En la segunda escritura reconocía que, de 4.140 pesos (equivalentes a 33.120 reales de plata) adeudados por Gurmendi, 11.040 de ellos eran de don José de San Víctores, caballero de Alcántara, 2.070 de don Pedro Torrado de Guzmán y 16.640 del veedor gaditano ya mencionado. Declaraba que él no tenía responsabilidad alguna en el buen fin del crédito de esas personas. El documento, que permanecería en el secreto del protocolo del escribano, se otorgaba tanto en interés de los ocultos prestamistas, que preservaban así sus derechos a reclamar la deuda, como en interés de Murillo, que se declaraba irresponsable en caso de que hubiera un fallido. En resumen, de los 9.660 pesos de la suma de ambos préstamos, equivalentes a 77.280 reales de plata doble, solo 20.010 reales podían pertenecer a Murillo, y, probablemente, no todos, pues José de Veitia era también poderdante de Aturiaque para cobrar en Portobelo y comprar mercancías. Los

${ }^{38}$ La equivalencia del cálculo, 19 reales el peso, debía ser la más habitual. La utilizada en la catedral para pagar al pintor sus obras en la sala capitular es de 18 reales y medio el peso en 1667 y principios de 1668 (HEREZA, Pablo: Corpus..., op. cit., pp, 402-404, doc. 148, y pp. 413-415, doc. 152b) y, a partir de 26 de mayo de 1668, a 19 reales (HEREZA, Pablo: Corpus..., op. cit., pp. 416-418, doc. 155).

${ }^{39}$ HEREZA, Pablo: Corpus..., op. cit., pp. 236-239, docs. 37 y 38.

${ }^{40}$ Ibidem, pp. 234-235, doc. 36.

${ }^{41}$ Juana Murillo, única hija conocida de Juan Agustín Lagares y Ana Murillo, casó con Aturiac en 1646 y debió de fallecer en 1650, en su cuarto viaje a Indias. HEREZA, Pablo: Corpus..., op. cit., p. 27. 
restantes reales eran de "tapados", personas que por su condición nobiliaria o por sus puestos relacionados con la Casa de la Contratación no querían aparecer como prestamistas.

El caso más llamativo es el de Juan Martínez de Soto, que Murillo declara que era veedor y residente en Cádiz. Su condición de residente en Cádiz sugiere una estancia temporal y es posible que fuera vecino de Sevilla ${ }^{42}$. También lo es que tuviera alguna relación con el capitán Pedro Martínez de Soto, casado con Isabel Paula Zurbarán, que apadrinaban en 9 de febrero de 1648 a una hija de Francisco de Zurbarán y su tercera esposa, Leonor de Tordera ${ }^{43}$. Juan Martínez de Soto participaba en el primer contrato con 22.080 reales y en el segundo con 16.640 reales, en total, casi la mitad de la suma de los dos créditos. Había varias clases de veedores relacionados con el comercio con América. Veitia, en su Norte de la Contratación, habla del veedor de contrabando, que visitaba las naves extranjeras (p. 17), del veedor y contador que viajaba en la capitana, que firmaba los despachos (p. 37) y daba relación de gastos del viaje (p. 63), de un veedor y contador de la artillería (p. 127), y sobre todo, con multitud de referencias, del veedor y contador de la Armada (pp. 141, 154, 164, entre otras). En todo caso, Martínez de Soto sería un oficial de designación real o nombrado por la Casa de Contratación de Sevilla con funciones equivalentes a las de un interventor, por lo que su participación en operaciones que debían liquidarse en dicha Casa de Contratación no podía estar bien vista.

Nos hemos ocupado con cierta amplitud del caballero alcantarino don José de San Víctores de la Portilla en otra publicación. Hemos citado ya a su padre don Jerónimo, que fue administrador general del almojarifazgo en 1643, santiaguista y miembro del Consejo de Hacienda ${ }^{44}$. Parece que el mismo don José disfrutó de ese puesto entre 1656 y 1658, si bien mediante un delegado por estar ausente ${ }^{45}$. Es el mismo personaje que era partícipe de una cantidad de 11.040

42 PASTELLS, Pablo: Historia de la Compañia de Jesús, en la provincia del Paraguay... Vol. 2. Madrid, 1915, Periodo Quinto... (1654-1668), p. 623. Según esta crónica, elaborada sobre fondos del Archivo de Indias, en 1654 había salido de Cádiz un buque con patente de corso propiedad de Juan Martínez de Soto cargado de mercancías y gente holandesa, que arribó al puerto de Tucumán a fines de ese mismo año, y que tres días después de descargar y salir de ese puerto le dieron fuego.

${ }_{43}$ CALZADA, Andrés Manuel y SANTA MARINA, Luys: Estampas de Zurbarán. Barcelona, 1929, p. 22, En 1659, este capitán era oficial de las Reales Aduanas. KINKEAD, Duncan T.: "The Last Sevillian Period of Francisco de Zurbaran”, Art Bulletin, 65, 1983, pp. 307-311, en especial la p. 310.

${ }^{44}$ CRUZ VALDOVINOS, José Manuel: Notas..., op. cit.

${ }^{45}$ CÁRCELES DE GEA, Beatriz: "Una visita de Hacienda a los almojarifazgos de Sevilla en el siglo XVII”, en ALLOZA APARICIO, Ángel y CÁRCELES DE GEA, Beatriz (coords.): Comercio y riqueza en el siglo XVII. Madrid, 2009, pp. 171-195, en especial la p. 190. 
reales en el crédito de Murillo contra José de Gurmendi. La vinculación familiar con los puestos oficiales relacionados con el comercio transoceánico, y, sobre todo, la condición nobiliaria del prestamista explica que ocultara estos negocios.

Nada sabemos del vecino de Cádiz llamado Miguel Mejías, al que correspondía un crédito de 5.520 reales en la obligación de Ipeñarrieta. En cambio, hay abundantes noticias del titular de la suma más pequeña, 2.070 reales, don Pedro Torrado de Guzmán, cuyo tratamiento de "don" justifica que ocultara el préstamo. Fue una persona muy vinculada a José de Veitia durante muchos años. En el título de contador mayor de averías expedido a favor de Veitia el 16 de octubre de 1653, consta expresamente su facultad de nombrar teniente que lo sirviera, y, al final, se reseña la designación de teniente de Torrado de Guzmán ${ }^{46}$. En 8 de febrero de 1655 fue padrino del bautismo de Francisca María Murillo, la única hija del pintor que llegó a adulta ${ }^{47}$. Era contador, pero, además, un celebrado -aunque no muy inspirado- poeta $^{48}$. Fernando de la Torre Farfán recogió y comentó el poema dedicado a la Inmaculada con que Torrado participó en el certamen que se celebró en Sevilla en 1662 sobre ese asunto convocado por la Hermandad del Santísimo Sacramento del Sagrario de la catedral ${ }^{49}$. El autor, que había sido secretario del certamen, deja constancia de que Torrado había participado en 1656 y 1659 en sendos concursos poético-religiosos. En el comentario sobre su persona le proclama sabio en todas las filosofías y estudioso de las ciencias químicas, conocedor de lenguas y hábil con la espada, si bien en el vejamen que de la Torre Farfán redacta - como era común en estas composiciones- llega a incluir afirmaciones tan insultantes como la siguiente: "[...] que quanto haze,/ Si a blanca lo vende, es cosa/ Para que lo compre nadie./ Con todo dize, que diestro,/ Nunca temerá empeñarse/ con Virgilio el más Carrança,/ con Ovidio el más Narbáez". La

${ }^{46}$ MONTOTO, Santiago: Don José de Veitia..., op. cit., pp. 25-33. Relata que lo adquirió por 60.000 reales de plata pagados a la viuda del anterior titular más 1.500 pesos de plata (28.500 reales de vellón) para la Hacienda pública por la facultad de poderlo servir mediante teniente; gozaba de un sueldo anual de 500 ducados y, además, los emolumentos propios del cargo. Al final del documento se indica: "Nombró por theniente a D. Pedro Torrado de Guzmán en 17 de noviembre de 1653".

${ }^{47}$ HEREZA, Pablo: Corpus..., op. cit., p. 288, doc. 69.

${ }^{48} \mathrm{Su}$ obra más conocida es Triunfo Inmaculado de la Emperatriz de Cielo, y Tierra, Maria, concebida sin mancha de culpa Original, en el primer instante de su Ser Compuesto por Don Pedro Torrado de Guzman, natural y vezino de la Villa de Feria, en Estremadura, y residente en esta Ciudad de Sevilla... Sevilla, 1669.

49 DE LA TORRE FARFÁN, Fernando: Templo panegirico, al certamen poetico, que celebro la Hermandad insigne del Smo. Sacramento, estrenando la grande fabrica del Sagrario nuevo de la Metropoli sevillana, con las fiestas en obsequio del Breve concedido por la Santidad de N. Padre Alexandro VII al primer instante de Maria Santissima Nuestra Señora sin pecado original... Sevilla, 1663, en especial las pp. 70-72. 
alusión a los empeños mezclada con la de los dos maestros de la esgrima ${ }^{50}$ podría encerrar una velada acusación a su actividad de prestamista. La amistad de Torrado con Veitia se prolongó muchos años después de que el primero pasara a ejercer la tesorería de la Casa de Contratación tras la muerte de Munibe ${ }^{51}$, como evidencia el soneto que compuso para celebrar la publicación del Norte de Contratación en 1672 y que se incluyó en sus páginas preliminares. Otro soneto con la misma función laudatoria y de presentación hizo Torrado para la primera publicación del jesuita Lorenzo Ortiz de Buxedo titulada Memoria, Entendimiento y Voluntad. Empresas que enseñan y persuaden su buen uso en lo moral y en lo político... ${ }^{52}$, donde glosaba la humildad del religioso. Ortiz es un interesante personaje que, además de los textos, hizo de su mano los grabados que ilustran los emblemas, encerrados en unas complicadas y elegantes tarjetas. Tuvo también relación con Murillo, pues apadrinó a su hijo Francisco en su confirmación celebrada el 19 de marzo de $1660^{53}$, y es probable que fuera el don Lorenzo para quien daba recuerdos Zurbarán en la carta dirigida a Murillo en 17 o 27 de septiembre de 1659 en que el pintor hizo el rasguño de una Inmaculada ${ }^{54}$.

El 7 de septiembre de 1652, Domingo de Ipeñarrieta, y Diego de Aremo, vecino de Sevilla, reconocían otro préstamo de Murillo, esta vez de 8.800 pesos de ocho reales de plata que devolverían en Portobelo a fin de noviembre de ese año. El 9 de septiembre, Murillo daba poder a tres viajeros de la flota, uno de ellos don José de Morales, maestre de la plata en la almiranta de los galeones que partían, para cobrar la deuda ${ }^{55}$. En ese viaje sucedió la quiebra con alzamiento de Domingo Ipeñarrieta, que había tomado a daño en Sevilla más de 160.000 pesos $^{56}$. Empezó a barruntarse en 1653 en Portobelo, con entregas del maestre inferiores a lo comprometido, y, a su vuelta a Sevilla, faltaron casi la mitad de las barras de plata y mercancías adeudadas. En 1654 fue prendido y encarcelado; en febrero de 1656, el Consejo de Indias evaluó el fraude en 35.000 pesos, de los que pertenecían 10.000 a la Real Hacienda y el resto a particulares. El quebrado fue condenado a muerte, pero se le indultó previa entrega de 5.000 pesos a la Real Hacienda. No sabemos la suerte que corrieron los 8.800 pesos prestados por $\mathrm{Mu}$ rillo en 1652 -solo o quizá con otros prestamistas- pero cabe suponer que les

${ }^{50}$ Se llamaban Jerónimo Sánchez de Carranza y Luis Pacheco de Narváez.

${ }^{51}$ MONTOTO, Santiago: Don José de Veitia..., op. cit., p. 14, indica que fue su teniente en este nuevo oficio don Andrés de Rubio y Sotomayor.

${ }^{52}$ Sevilla, 1677, impr. de Juan Francisco de Blas.

${ }^{53}$ HEREZA, Pablo: Corpus..., op. cit., pp. 354-355, doc. 107.

${ }^{54}$ Ibidem, p. 343, doc. 100.

${ }_{55}$ Ibid., pp. 274-275, doc. 56.

56 DOMÍNGUEZ ORTIZ, Antonio: "La quiebra de Domingo de Ypeñarrieta, maestre de la plata”, en Estudios Americanistas, Real Academia de la Historia. Madrid, 1998, pp. 275-294. 
alcanzó, al menos en parte, la quiebra del maestre de la plata. Más aún ante el contenido del siguiente documento que comentamos.

En 10 de julio de 1653, Murillo otorgaba una escritura en que cedía a favor del alguacil mayor de la Audiencia de Sevilla y caballero de Santiago, don Antonio del Castillo Camargo, el título del crédito que tenía contra Ipeñarrieta por los 5.520 pesos prestados en 1650 -que eran en gran parte del veedor de Cádiz y de Miguel Mejías-, para que los cobrara cuando llegara la flota del general Mencos, reconociendo que él los había cobrado ya del cesionario ${ }^{57}$. Aunque era muy pronto para que hubieran llegado a Sevilla las noticias sobre el incumplimiento de pagos por parte de Ipeñarrieta, seguramente Veitia tenía ya algunos conocimientos sobre el asunto. Murillo buscó entonces quien le comprara ese crédito que se anunciaba fallido, y encontró a Castillo Camargo, persona también muy avisada y relacionada con Veitia por el importante papel que ejercía en el Consu$\operatorname{lado}^{58}$. El documento calla sobre el precio de la cesión, pero debió de tener una rebaja importante sobre el nominal, dado el alto riesgo de no cobrar.

Todavía se conocen dos préstamos marítimos más realizados por Murillo. El primero, de 5 de julio de 1655, se sabe por la escritura del capitán Antonio Martín de Torres ${ }^{59}$ donde reconocía que el pintor le había entregado 8.000 reales de plata (1.000 pesos), y se obligaba a devolvérselos a fin de diciembre de ese mismo año. La cantidad es notablemente inferior a la de las dos operaciones anteriores y cabe suponer que fuera toda de Murillo. El préstamo no se vinculaba aparentemente a ningún viaje de la flota, pero la condición de capitán del prestatario y la duración del préstamo, unos seis meses, sugieren que la finalidad era aprestar el buque que tenía a su cargo o comprar mercancías para llevar a Indias. Las vicisitudes de la salida de la flota de ese año, a consecuencia del bloqueo inglés de la bahía de Cádiz, que duró hasta octubre, ocasionaron grandes daños a los comerciantes ${ }^{60}$. Murillo recuperará la totalidad de su préstamo más de ocho años después de vencido el plazo, ya que dio carta de pago en 18 de enero de $1664^{61}$.

${ }^{57}$ HEREZA, Pablo: Corpus..., op. cit., pp. 284-285, doc. 65. En CRUZ VALDOVINOS, José Manuel: "Murillo en Madrid", op. cit., se recuerda que don Antonio del Castillo Camargo era caballero de Santiago y uno de los sevillanos que prestaron testimonio favorable a Velázquez en su información sobre el hábito. ATERIDO, Ángel (ed.): Corpvs velazqueño. Madrid, 2000, p. 427, testigo $\mathrm{n}^{\circ} 138$.

${ }_{58}$ HEREDIA HERRERA, Antonia: Los dirigentes oficiales del Consulado de Cargadores a Indias, en III Jornadas Andalucía y América. T. I. Sevilla, 1985, pp. 217-236, en especial p. 235.

59 Tan solo hemos localizado una referencia a este marino, unos autos seguidos en 1624 en la Casa de Contratación entre él y Bartolomé del Oro sobre el pago de 12 pipas de vino. AGI, Contratación, 813.8.

60 CARRASCO GONZÁLEZ, María Guadalupe: Comerciantes y casas de negocios en Cádiz, 1650-1700. Cádiz, 1997, p. 25.

${ }^{61}$ HEREZA, Pablo: Corpus..., op. cit., p. 389, doc. 132. 
El segundo préstamo fue el reconocido en escritura de 14 de noviembre de 1657 por el capitán Jerónimo de Cortabarría, que partía con su buque hacia Santo Domingo. Le avalaban el capitán Pedro de Echave Yasu y el maestre de la plata Francisco de Ayalde. Lo prestado eran 2.225 pesos de 8 reales de plata, equivalentes a 17.800 reales de plata y habían sido usados para avituallar el buque y comprar mercaderías. Debían ser devueltos en Santo Domingo a fin del mes de abril de $1658^{62}$. Como de costumbre, Murillo dio poder a tres personas que marchaban con esa flota y que eran vecinos de Santo Domingo, una de ellas José de Morales, al que ya había apoderado en $1652^{63}$. Cortabarría y Ayalde fueron encausados por las autoridades de la Casa de Contratación en 1659 por haber hecho paradas en puertos no autorizados y por denuncias relativas a las mercancías ${ }^{64}$.

\section{La provisión de buques y otros asuntos de Indias}

Otra faceta del Murillo negociante tiene relación con la provisión de alimentos para las naves que marchaban a América. El 27 de marzo de 1653, el pintor daba poder a cuatro personas para cobrar de don Diego de Portugal, general de la flota que iba a marchar a Tierra Firme, o de cualquier oficial real que tuviera encargo de pagar provisiones de la armada, 13.210 reales de plata, que los tenía asignados por libramientos de don Bernabé Ochoa de Chinchetru ${ }^{65}$, proveedor general, en otros dos libramientos hechos en el Pardo en el pasado enero, uno de 1.210 reales a favor de Francisco de Medina y otro de 234.600 reales a favor de don Francisco Gaspar de Solís por el valor de 391 pipas de vino ${ }^{66}$. En este último, correspondían a Murillo 12.000 reales. Solís, calatravo y señor de Ojén y otros lugares, era cosechero ${ }^{67}$, pero sus existencias no debieron de ser suficientes para hacer la provisión de vino deseada por Ochoa de Chinchetru, y completó la cantidad adquiriendo más cantidad de otras personas, entre ellas Murillo. El precio de cada pipa era 600 reales, por lo que al pintor corresponderían 20 pipas en la libranza de Solís y otras dos en la de Francisco de Medina, cuyo precio unitario sería 605 reales.

También había participado Murillo en los suministros de la flota que salía ese mismo año 1653 comandada por el general Juan de Echeverri, en este caso con

62 Ibidem, pp. 333-335, doc. 95.

${ }_{63}$ Ibid., pp. 335-337, doc. 96.

${ }^{64}$ AGI, Contratación, 187.

${ }^{65}$ Recordaremos que fue retratado por Carreño de Miranda en 1660 (Hispanic Society of America, Nueva York).

${ }^{66}$ HEREZA, Pablo: Corpus..., op. cit., pp. 277-279, doc. 60.

${ }^{67}$ GUTIÉRREZ NÚÑEZ, Francisco Javier: "Los Solís Manrique (s. XVI-XIX). Señores de Ojén y marqueses de Rianzuela”, Takurunna, 2, 2012, pp. 217-272. 
una entrega de pasas y almendras. En 11 de noviembre de 1653, daba poder sucesivo a tres viajeros que se dirigían a Portobelo en dicha flota, para que cobraran allí 3.325 reales que le correspondían en el libramiento hecho en el Pardo en 30 de enero a favor de Francisco de Medina Quintero -sin duda, el mencionado en la operación anterior-por la provisión a dicha flota de catorce quintales y medio de pasas largas y siete quintales y medio de almendra, cuyo importe total no se especifica. También era don Bernabé Ochoa de Chinchetru quien había librado a favor de Murillo los mencionados 3.325 reales a cobrar en el libramiento de mucho mayor importe hecho a favor de Medina ${ }^{68}$.

A efectos de simple recordatorio, aludiremos al envío de ropa y hierro en 1662 que menciona Quiles realizado, al parecer, a través del capitán Diego de la Parra, una operación en que participaron Murillo y el marqués de Legarda ${ }^{69}$. Sería de desear la pronta publicación desarrollada de esta noticia.

Aún se ocupará el pintor de cobrar como albacea de su prima María Murillo los préstamos y envíos de mercancías en buques que marchaban a América y que quedaron pendientes de pago o devolución a su muerte en junio de 1679. Su difundo marido, el pintor Francisco Terrón, y ella misma estaban habituados a los negocios americanos ${ }^{70}$. El 5 de octubre de 1679, Murillo daba carta de pago a Sebastián de Solórzano que le había entregado 150 ducados de plata por un préstamo y otros 94 por la venta de 200 pares de calcetas que confió al capitán Francisco de Gorrochategui para que las llevase a Indias ${ }^{71}$.

Fecha de recepción: 14 de julio de 2018

Fecha de aceptación: 5 de febrero de 2019

${ }^{68}$ HEREZA, Pablo: Corpus..., op. cit., pp. 286-287, doc. 66.

${ }^{69}$ QUILES GARCÍA, Fernando: Casos y cosas de la América hispana, desde Sevilla. Siglos XVII-XVIII, en FERNÁNDEZ VALLE, María de los Ángeles; OLLERO LOBATO, Francisco y REY AHFILED, William (eds.): Arte y patrimonio en España y América. Montevideo, 2014, pp. 141-161, en especial p. 143.

${ }^{70}$ María Murillo era hija del pintor Antonio Pérez, hermano de la madre de Murillo. Francisco Terrón declaraba en 20 de agosto de 1670 que entregó a uno de los hermanos de María, que marchó a Indias, una serie de lienzos para su venta. KINKEAD, Duncan T.: Pintores..., op. cit., p. 537.

${ }^{71}$ HEREZA, Pablo: Corpus..., op. cit., pp. 509-511, doc. 233. 